\begin{tabular}{|c|c|c|}
\hline \multirow{3}{*}{$\begin{array}{r}\text { Case Reports in } \\
\text { Gastroenterology }\end{array}$} & \multirow{2}{*}{\multicolumn{2}{|c|}{ Case Rep Gastroenterol 2015;9:15-19 }} \\
\hline & & \\
\hline & $\begin{array}{l}\text { DOI: 10.1159/000373882 } \\
\text { Published online: January 16, } 2015\end{array}$ & $\begin{array}{l}\text { (c) } 2015 \text { S. Karger AG, Basel } \\
1662-0631 / 15 / 0091-0015 \$ 39.50 / 0 \\
\text { www.karger.com/crg }\end{array}$ \\
\hline & \multicolumn{2}{|c|}{$\begin{array}{l}\text { This is an Open Access article licensed under the terms of the Creative Commons } \\
\text { Attribution-NonCommercial } 3.0 \text { Unported license (CC BY-NC) (www.karger.com/OA- } \\
\text { license), applicable to the online version of the article only. Distribution permitted for non- } \\
\text { commercial purposes only. }\end{array}$} \\
\hline
\end{tabular}

\title{
Laparoscopic Resection of Schwannoma of the Ascending Colon
}

\author{
Yoshihiko Tashiro $^{a}$ Fumio Matsumoto ${ }^{a}$ Keiko Iwama $^{a}$ Ai Shimazu $^{a}$ \\ Sei Matsumori ${ }^{a}$ Shigeo Nohara ${ }^{a}$ Hiroyoshi Miura $^{a}$ Masahiko Takei ${ }^{a}$ \\ Koji Namekata ${ }^{a}$ Masaru Takase $^{b}$ Motoi Okada $^{b}$ Hidenori Tsumura $^{a}$ \\ Departments of a Surgery and ${ }^{b}$ Pathology, Koshigaya Municipal Hospital, Koshigaya, Japan
}

\section{Key Words}

Laparoscopic surgery $\cdot$ Schwannoma

\begin{abstract}
Schwannomas of the colon are rare and difficult to diagnose preoperatively. We report a case of schwannoma of the ascending colon that was resected laparoscopically. A 64-year-old woman was referred to our hospital by her local clinic for further evaluation and management of a submucosal tumor of the ascending colon. A definitive preoperative diagnosis could not be reached despite examinations. Gastrointestinal stromal tumor, leiomyoma and lymphoma were the differential diagnoses. We performed a laparoscopic right hemicolectomy with D2 lymph node dissection. Histological findings with hematoxylin-eosin staining revealed spindle-like tumor cells, and immunohistochemical analysis showed that the tumor was positive for S-100 but negative for c-kit, CD34, smooth muscle actin and desmin, with a $\mathrm{Ki}-67$ index of $<5 \%$. Thus, the diagnosis in this case was benign schwannoma of the ascending colon.

(c) 2015 S. Karger AG, Basel
\end{abstract}

\section{Introduction}

Schwannomas are derived from Schwann cells and are rare in the digestive tract. Schwannomas can be found throughout the body along the peripheral nerves, but isolated schwannomas of the colon without associated neurofibromatosis are extremely rare among schwannomas in the digestive tract. The incidence of schwannoma in the intestine has been reported to be $2-6 \%$ of all submucosal tumors (SMTs) of the intestine [1]. The preoperative diagnosis of schwannoma is difficult, but the majority of schwannomas are benign. However, 
Tashiro et al.: Laparoscopic Resection of Schwannoma of the Ascending Colon

incompletely resected tumors occasionally transform into malignant ones [2]. Therefore, radical surgery is the standard treatment. Currently, laparoscopic surgery is widely applied as a minimally invasive technique for various colorectal diseases. Here, we describe a case of schwannoma of the ascending colon that was resected with laparoscopic right hemicolectomy.

\section{Case Report}

A 64-year-old woman with no past medical history and a family history of neurofibromatosis was referred to her local hospital for a routine health examination. On screening colonoscopy, a 5-cm SMT in the ascending colon was discovered. She presented to our hospital for further evaluation and treatment. Her physical examination was noncontributory and her laboratory data was unremarkable. Abdominal ultrasonography revealed a well-defined tumor $4 \mathrm{~cm}$ in diameter, close to the ascending colon. Barium enema showed deformity of the wall of the ascending colon, close to the ileocecum. Contrast-enhanced computed tomography showed a well-defined homogeneously enhanced tumor in the ascending colon (fig. 1b). Colonoscopy showed a 5-cm SMT in the ascending colon (fig. 1a). The differential diagnoses were gastrointestinal stromal tumor, lymphoma and leiomyoma.

We performed a laparoscopic right hemicolectomy with D2 lymph node dissection and a functional end-to-end anastomosis. The tumor, $50 \times 30 \times 25 \mathrm{~mm}$ in size, was covered by normal colonic mucosa of the ascending colon (fig. 2a). The tumor was whitish in color and located from the submucosa to the subserosa on the axial plane (fig. 2b). Histological findings of the hematoxylin-eosin-stained specimen revealed spindle-like tumor cells (fig. 2c). Immunohistochemical staining demonstrated lack of reactivity to CD117 (c-kit), CD34 and smooth muscle actin, with positive cytoplasmic reactivity to $S-100$ protein (fig. 2d). The MIB-1 index was $<5 \%$. Lymph nodes with no evidence of metastasis were identified. The histological diagnosis was benign schwannoma of the ascending colon. The patient's recovery was uneventful and she was discharged home on postoperative day 14. At the 4-month follow-up, the patient was doing well, without any evidence of recurrence.

\section{Discussion}

Schwannomas are neoplasms that originate from Schwann cells in the peripheral nerve of the limbs, neck and head [3]. Schwannomas in the digestive tract are rare, and schwannomas in the colon are extremely rare. The proportion of schwannomas among gastrointestinal mesenchymal tumors in the colon was about 3\% [4].

It seemed that a preoperative diagnosis of schwannomas is difficult to reach because these lesions appeared as SMTs, meaning that the mucosal biopsy specimens would likely be normal. Inagawa et al. [5] demonstrated that the rate of accurate preoperative diagnosis of benign schwannoma was only $15.2 \%$. The diagnosis of schwannomas through histopathological examination of hematoxylin-eosin-stained specimens is not accurate enough. Therefore, immunohistochemical analysis is required for increased accuracy. A diagnosis of schwannoma is considered if positive expression of S-100 protein and negative expression of c-kit, $\alpha$-smooth muscle actin, CD34, desmin and cytokeratins are observed [6].

Recently, endoscopic ultrasonography-guided fine needle aspiration (EUS-FNA) with immunohistochemical analysis has been attempted to obtain a preoperative diagnosis of SMT. For gastrointestinal stromal tumors, the reported preoperative diagnostic accuracy of 
Tashiro et al.: Laparoscopic Resection of Schwannoma of the Ascending Colon

EUS-FNA, assessed using immunohistochemical analysis of surgically resected cases, ranged from 91 to $100 \%$ [7, 8]. The accuracy of diagnosis using EUS-FNA with immunochemistry is excellent, but the accuracy of preoperative diagnosis can be increased. It cannot be used to distinguish benign or malignant behavior because tumor malignancy is based on the Ki-67 labeling index (MIB-1), whereby highly reproducible immunopositivity for MIB-1 indicates malignancy [9]. MIB-1 was $<5 \%$ in this case.

Complete local excision with a sufficient surgical margin is generally considered to be the correct treatment of colonic schwannomas because the risk of malignant transformation is extremely low [5]. However, if the preoperative diagnosis is unknown, radical resection with lymphadenectomy is acceptable for schwannomas because of the possibility of malignancy. In addition, Braumann et al. [10] suggested that in the absence of an adequate preoperative diagnosis, the extent of excision should be determined by the characteristics of the tumor, such as size, location and consistency.

Regardless of the stage of colon cancer, randomized trials of laparoscopic versus open surgery for colon cancer showed no difference in overall survival, intraoperative complications, postoperative complications, and so on [11-13]. A randomized trial of laparoscopic versus open surgery for SMT of the colon has not been conducted because the occurrence of SMT in the colon is low. If malignancy is suspected, radical resection with lymphadenectomy would be performed. In the present case, we could not obtain a preoperative diagnosis of schwannoma and confirmation of its benign status. Therefore, we performed laparoscopic right hemicolectomy with lymphadenectomy because there was a slight possibility of malignancy. The histological diagnosis was benign schwannoma of the ascending colon.

In conclusion, laparoscopic surgery is acceptable and useful for schwannomas of the colon, almost all of which are benign tumors.

\section{Disclosure Statement}

The authors have no conflicts of interest or financial ties to disclose.

\section{References}

1 Daimaru Y, Kido H, Hashimoto H, Enjoji M: Benign schwannoma of the gastrointestinal tract: a clinicopathologic and immunohistochemical study. Hum Pathol 1988;19:257-264.

-2 Fotiadis CI, Kouerinis IA, Papandreou I, Zografos GC, Agapitos G: Sigmoid schwannoma: a rare case. World J Gastroenterol 2005;11:5079-5081.

-3 Skopelitou AS, Mylonakis EP, Charchanti AV, Kappas AM: Cellular neurilemoma (schwannoma) of the descending colon mimicking carcinoma: report of a case. Dis Colon Rectum 1998;41:1193-1196.

4 Miettinen M, Shekitka KM, Sobin LH: Schwannomas in the colon and rectum: a clinicopathologic and immunohistochemical study of 20 cases. Am J Surg Pathol 2001;25:846-855.

-5 Inagawa S, Hori M, Shimazaki J, Matsumoto S, Ishii H, Itabashi M, Adachi S, Kawamoto T, Fukao K: Solitary schwannoma of the colon: report of two cases. Surg Today 2001;31:833-838.

-6 Nonose R, Lahan AY, Santos Valenciano J, Martinez CA: Schwannoma of the Colon. Case Rep Gastroenterol 2009;3:293-299.

7 Ando N, Goto H, Niwa Y, Hirooka Y, Ohmiya N, Nagasaka T, Hayakawa T: The diagnosis of GI stromal tumors with EUS-guided fine needle aspiration with immunohistochemical analysis. Gastrointest Endosc 2002;55: 37-43.

8 Okubo K, Yamao K, Nakamura T, Tajika M, Sawaki A, Hara K, Kawai H, Yamamura Y, Mochizuki Y, Koshikawa $\mathrm{T}$, Inada K: Endoscopic ultrasound-guided fine-needle aspiration biopsy for the diagnosis of gastrointestinal stromal tumors in the stomach. J Gastroenterol 2004;39:747-753.

-9 Tsunoda C, Kato H, Sakamoto T, Yamada R, Mitsumaru A, Yokomizo H, Yoshimatsu K, Ogawa K, Aiba M, Haga $\mathrm{S}$ : A case of benign schwannoma of the transverse colon with granulation tissue. Case Rep Gastroenterol 2009;3:116-120. 
Tashiro et al.: Laparoscopic Resection of Schwannoma of the Ascending Colon

10 Braumann C, Guenther N, Menenakos C, Junghans T: Schwannoma of the colon mimicking carcinoma: a case report and literature review. Int J Colorectal Dis 2007;22:1547-1548.

11 Leung KL, Kwok SP, Lam SC, Lee JF, Yiu RY, Ng SS, Lai PB, Lau WY: Laparoscopic resection of rectosigmoid carcinoma: prospective randomised trial. Lancet 2004;363:1187-1192.

$\$ 12$ Clinical Outcomes of Surgical Therapy Study Group: A comparison of laparoscopically assisted and open colectomy for colon cancer. N Engl J Med 2004;350:2050-2059.

$\$ 13$ Lacy AM, García-Valdecasas JC, Delgado S, Castells A, Taurá P, Piqué JM, Visa J: Laparoscopy-assisted colectomy versus open colectomy for treatment of non-metastatic colon cancer: a randomised trial. Lancet 2002;359:2224-2229.
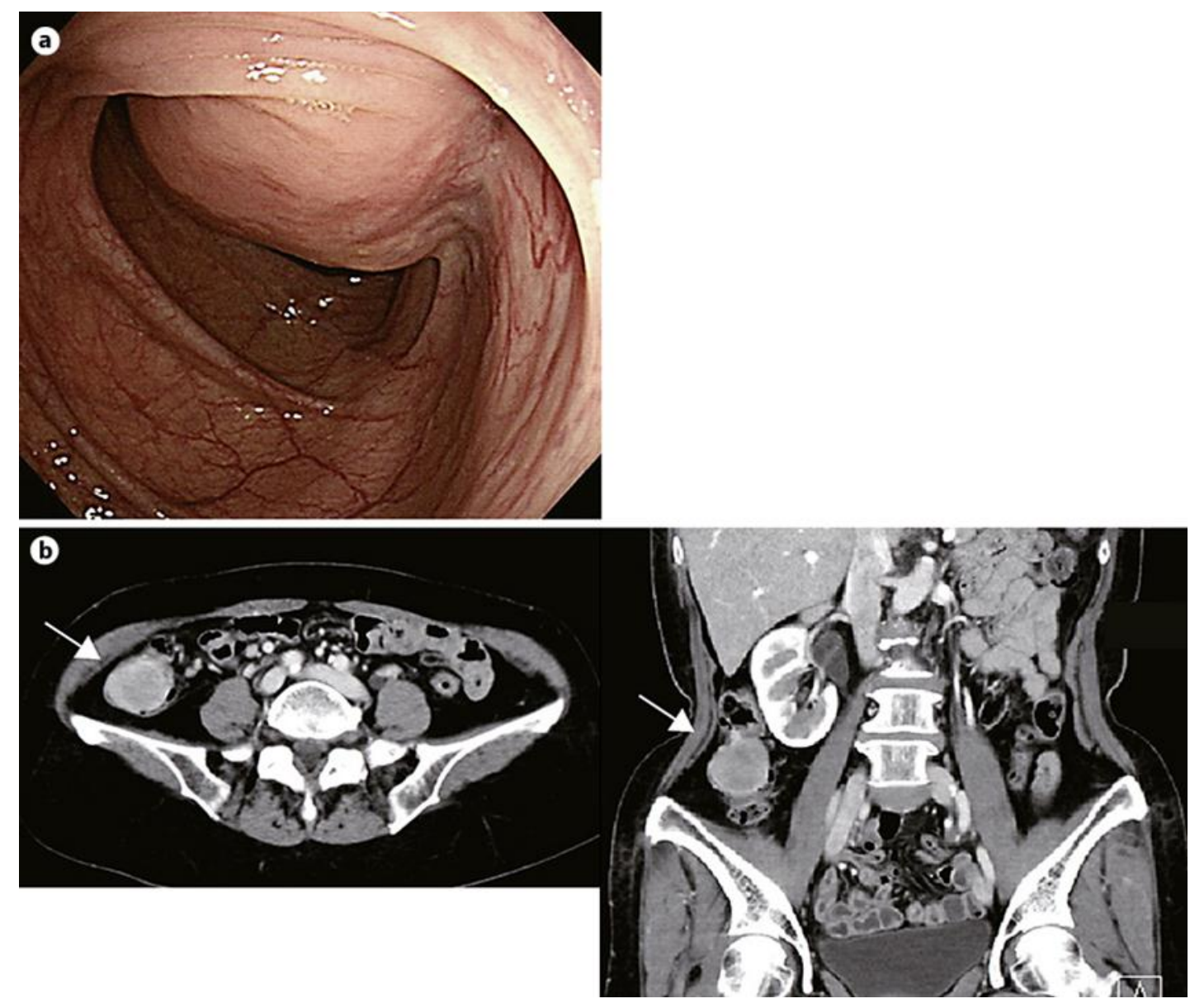

Fig. 1. a Colonoscopy showed a 5-cm SMT in the ascending colon. b Abdominal computed tomography revealed a tumor in the ascending colon (arrows). 


\begin{tabular}{ll|l} 
Case Reports in & \multicolumn{2}{l}{} \\
\cline { 2 - 3 } Gastroenterology & Case Rep Gastroenterol 2015;9:15-19 \\
\cline { 2 - 3 } & DOI: 10.1159/000373882 & $\begin{array}{l}\text { ○ 2015 S. Karger AG, Basel } \\
\text { www.karger.com/crg }\end{array}$ \\
\cline { 2 - 3 } & Tashiro et al.: Laparoscopic Resection of Schwannoma of the Ascending Colon
\end{tabular}
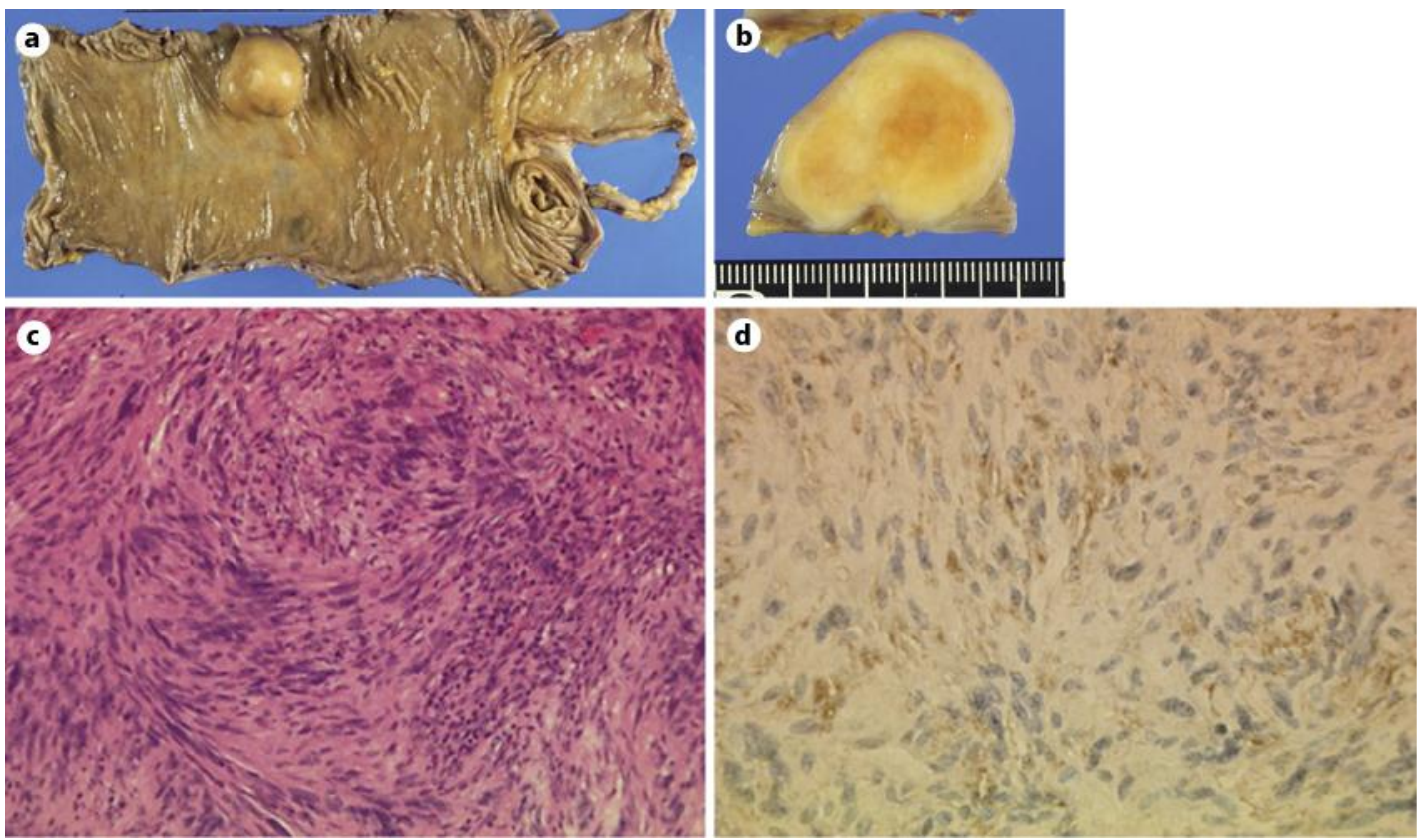

Fig. 2. a The resected specimen showed a SMT in the ascending colon, with dimensions of $50 \times 30 \times$ $25 \mathrm{~mm}$. b The tumor showed a whitish fibrotic and firm cut surface without definitive hemorrhage or necrosis. c The tumor was composed of whorled arranged spindle cells (hematoxylin-eosin staining, $\times 40)$. $d$ The tumor showed immunoreactivity to $S-100(\times 40)$. 